\title{
Some Pertinent Facts about Cebu and its Leprosy Problem.
}

\author{
JOSE RODRIGUEZ,
}

Geography.

CEBU is an elongated island barely 36 kilometres at its widest portion, with a length of 223 kilometres, and a total area of 4,836 square kilometres. The province comprises a considerable number of minor islands, of which only 14 have an area of one square mile or more. The mainland lies between $123^{\circ}-17^{\prime}-34^{\prime \prime}$ and $124^{\circ}-4^{\prime}-4^{\prime \prime}$ East Longitude, $9^{\circ}-24^{\prime}-46^{\prime \prime}$ and $11^{\circ}-17^{\prime}-11^{\prime \prime}$ North Latitude.

The highest peak is Mt. Uling, 1,013 metres, located at the central part of the island. From this peak, the land falls gradually on all sides to form the central plateau. The coastal plains are very narrow, widening only around the capital, Cebu, and at the towns of Tuburan and Bogo.

The soil is porous and so thin that the coral subsoil crops out of the surface even in the most fertile regions.

According to the 1918 census, there are 252,316 hectares of agricultural land of which only 51 per cent. were cultivated.

The principal crops are corn, coconuts, sugar-cane, peanuts, bananas, pineapples, camotes, maguey, and kapok.

The island is rich in minerals, the most important being coal and gold. The government cement plant at Naga turns out good cement, and the supply of the crude material is unlimited. Good fishing is to be had along the coast.

The estimated population of Cebu province as at December 31st, 1929, was 994,365.

\section{Climate.}

There is one first-class meteorological station located at the capital, and five rain stations distributed throughout the province.

The average means of upper and lower extremes of temperature are $35.1^{\circ} \mathrm{C}$. and $19 \cdot 9^{\circ} \mathrm{C}$. respectively, with an absolute mean of $15.2^{\circ} \mathrm{C}$. The extreme regularity in the sequence of the normal diurnal, monthly, and annual changes of temperature is most remarkable.

The average annual rainfall is low, being only $1,494 \cdot 0$ $\mathrm{mm}$. compared to the average of $2,366 \cdot 1 \mathrm{~m} . \mathrm{m}$. for the entire archipelago. This province is one of the driest in the Philippines. However, the rainfall is distributed quite evenly throughout the year, so that there is only a short dry season lasting from one to three months. 
Cebu has the lowest annual mean humidity of all the stations in the Philippines. The chief characteristic of the Cebu climate is the extremely little variation in the temperature, rainfall, and humidity from month to month and from year to year.

\section{History of Leprosy in Cebu.}

The manner by which leprosy was introduced in Cebu remains to be fully established. It is now practically certain that those who ascribe the introduction of leprosy into the Philippines through the arrival of 130 Japanese lepers in 1630 , are in error and that the disease was already prevalent in certain regions before that period. Guerrero is inclined to believe that the disease was introduced here by the original Malay settlers who in turn got it from their ancient Hindu colonisers.

No written records previous to the beginning of the nineteenth century regarding leprosy in Cebu are available. In 1817, a Hospital de San Lazaro was built by the Bishop of Cebu. An enterprising health official who advocated the forcible segregation of lepers in one of the near-by islands, estimated their number to be around three thousand in 1895.

Incidence of Leprosy.

It is, of course, next to impossible to determine the incidence of leprosy in any region with any degree of accuracy because the exact number of patients is never known.

Since 1902 to 31st December, 1929, 5,290 lepers have been discovered in this province. Of this number, 4,844 eventually reached Culion, which, however, was not established until 1906. The difference between the two figures indicates the number of those who had died between 1902 and 1906 and also those who had been released at Cebu or had been retained here. The total admissions to Culion since its establishment in 1906 to 31st December, 1929, is 19,000 cases.

Of the total of 5,290 collected in the province of Cebu, 1,393 or almost one quarter came from the capital itself.

In order to determine the relative frequency of leprosy in 52 municipalities in the province, the incidence based on the number of cases collected from each municipality since 1902, and the estimated population of each as at 3lst December, 1929, was determined. The figure obtained ranged from 0.4 per 1,000 population, to 26 per 1,000 collected over a period of 28 years. The average for the province is around fivelepers collected in 28 years for every 1,000 inhabitants or about one case per 1,000 inhabitants every 
$5 \frac{1}{2}$ years. It must, of course, be remembered that these figures do not represent the actual incidence of leprosy in these places, they merely serve to indicate the relative incidence of the disease in the different towns.

The distribution has been found to be distinctly " spotted " or focal. There are municipalities where the disease may be said to be practically non-existent; the few cases reported from them probably came originally from the more heavily infected towns. On the other hand, there are other towns that are quite heavily infected (see table at end).

The principal focus of the disease in the province may be enclosed within a circle with a radius of about 20 kilometers, having the heart of the capital as its centre. This area with its population of around 125,000 people by the end of 1929 , representing only one-eighth of that of the province and about 1 per cent. of that of the Philippines, has produced 2,349 lepers since 1902, or about three-sevenths of the total collected from the province and one-eighth of all the admissions to Culion.

The incidence was correlated with the climate whenever this could be determined for the various towns. The climatic conditions of different towns showing such marked differences of incidence were found to be so similar that the climate must play a very insignificant rôle in determining the incidence of leprosy in Cebu.

Influence of density of population on incidence of leprosy.

In preparing the data given in the table appearing at the end of this paper, the density of population was based on the population as of 1929, per hectare of cultivated territory. By simple inspection of the table, the relation of the density of the population to the incidence is not quite apparent, but when the data is treated biometrically to determine the degree of correlation, the result becomes very definite. The correlation figure was found to be $3335-$ $\cdot 08477$, indicating a very high degree of correlation.

\section{Future Plans.}

During the present year, a thorough epidemiological survey of the more important foci of the disease in Cebu will be undertaken, in conjuction with the campaign of eradication. The former dwelling places of all the lepers collected from these foci since 1902 are now being located. Particular attention will be paid to such factors as the economic condition, habits, main occupations, and sources of food of the inhabitants, as well as the kind of soil, water supply and the flora and fauna of the heavily infected villages as compared with the uninfected ones. 
Table giving the relative incidence of leprosy and the density of population per hectare of cultivated territory in each municipality.

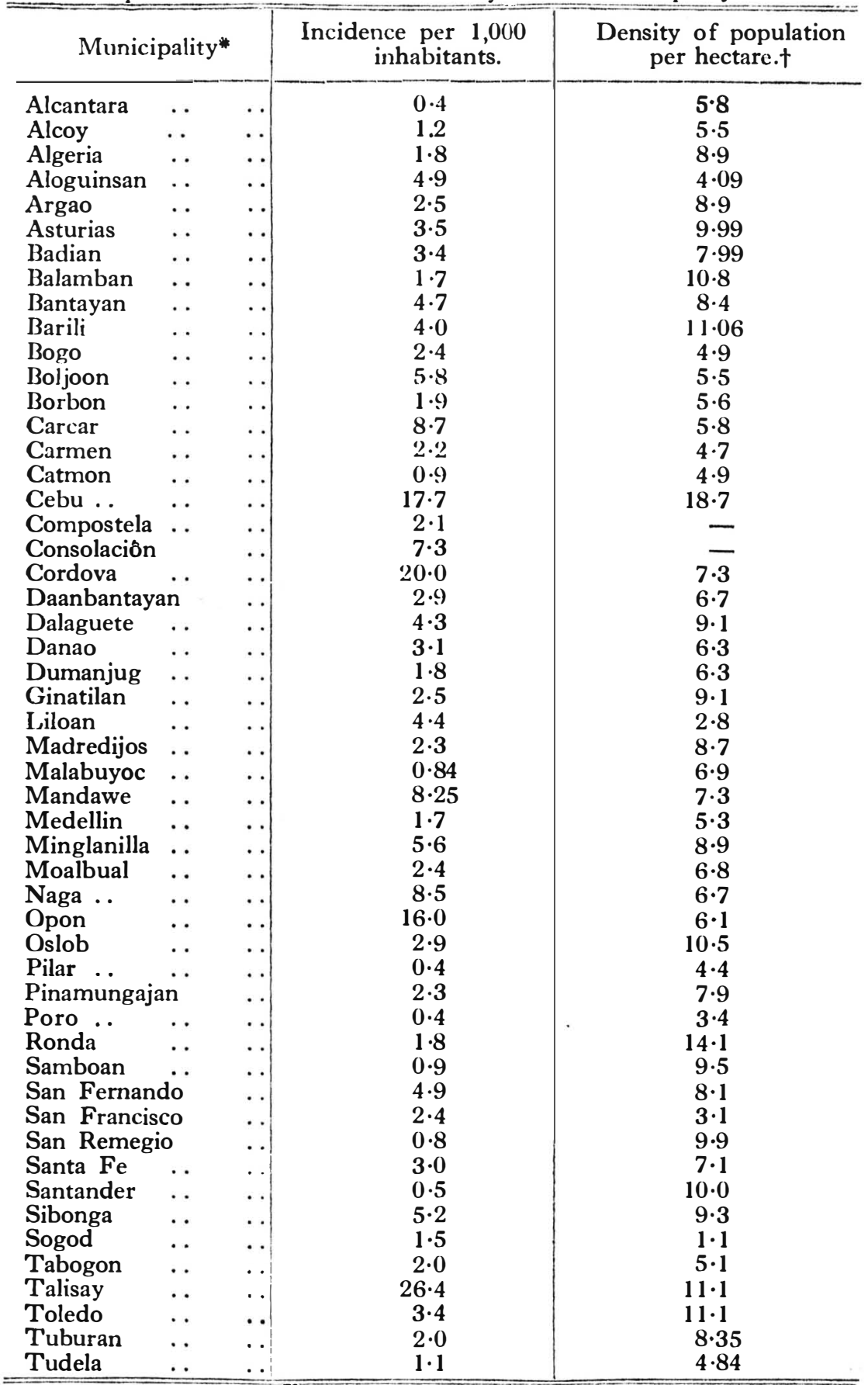

* The municipalities of Compostela and Consolaciôn are not included because no data as to the area of their respective cultivated lands could be obtained.

+ Population as of December 31st, 1929, and area of cultivated territory as per Census of 1918 . 